\title{
E2F Transcription Factor Family
}

National Cancer Institute

\section{Source}

National Cancer Institute. E2F Transcription Factor Family. NCI Thesaurus. Code

C129647.

A family of transcription factors that bind to the consensus sequence 5'-TTTC[CG]CGC-3'

and regulate the transcription of genes involved in cell cycle regulation, DNA repair and DNA replication. 